\title{
The acquisition of a running response as a function of odor buildup, squad rotation, and introduction of naive subjects
}

\author{
ROBERT E. PRYTULA \\ Middle Tennessee State University, Murfreesboro, Tennessee 37132 \\ and \\ STEPHEN F. DAVIS and J. J. FANNING \\ Emporia State University, Emporia, Kansas 66801
}

\begin{abstract}
A three-phase experiment was conducted in which rats received a double-alternation schedule of reward and nonreward. During Phase 1, the baseline period, double-alternation behavior was displayed earlier and more strongly by subjects run last in the daily sequence. This finding suggests that both reward and nonreward odor cues are cumulative over subjects. During Phase 2, a subject-rotation procedure was initiated; that is, each day the last subject in the previous day's running sequence was moved to the first position in the sequence, etc. Rotation to the first position in the group led to an immediate disruption of responding. During Phase 3, two naive rats were inserted at the beginning of the running sequence and two at the end. The results, which showed that the naive animals placed at the end of the sequence acquired the patterning response much faster than those placed in the beginning positions, are interpreted as reflecting preparedness to respond to such intensified odors.
\end{abstract}

Over the past 14 years, evidence has accumulated indicating that rats can communicate with each other via odors about the nature of impending goal events (e.g., Ludvigson \& Sytsma, 1967; Prytula \& Davis, 1976). Although the exact nature of the proposed chemical signals is not known yet, behavioral evidence does suggest that rats excrete different substances on reward (R) and nonreward $(N)$ trials. Furthermore, these $\mathrm{R}$ and $\mathrm{N}$ odors have been shown to elicit unconditioned approach and avoidance tendencies (Mellgren, Fouts, \& Martin, 1973), as well as having discriminative cue properties (Ludvigson, 1969).

In the runway situation, double-alternation schedules (e.g., RRNNRRNN) have been frequently used (Ludvigson \& Sytsma, 1967; Prytula \& Davis, 1976) to investigate the behavioral effects of such odor cues. In this situation, all subjects typically receive Trial 1 before Trial 2, and so on. Under these conditions, all subjects except the first run fast on $R$ trials and slowly on $\mathrm{N}$ trials, with this effect being most pronounced in the goal section of the runway. Such appropriate patterning under the doublealternation schedule has been cited as evidence for

This research was supported in part by a Faculty Research grant from Middle Tennessee State University to the first author, and a Research and Creativity grant from Emporia State University to the second author. Portions of this paper were presented at the Annual Meeting of the Psychonomic Society, St. Louis, Missouri, 1980. the operation of odor cues, because it is assumed that this schedule, and hence the control of behavior, is beyond the memory capabilities of the rat (Capaldi, 1971; Seago, Ludvigson, \& Remley, 1970).

Much of the odor research has typically used seven or fewer animals (Ludvigson \& Sytsma, 1967; Prytula \& Davis, 1976) and has yielded considerable information about small groups of rats alternately exposed to the odors of reward and nonreward. One question not addressed by these studies, however, is what the effects of odor accumulation are when a large group of animals is run. In the studies conducted to date, discriminative responding has been observed primarily in the goal section of the runway. With a greater number of animals, and potentially greater odor accumulation, odors should disseminate farther back in the apparatus, sustaining behavior in the run and, possibly, the start sections. By arbitrarily dividing this larger group into "low buildup" (first) and "high buildup" (last) subsquads, the between-groups variable of odor accumulation and influence could easily be examined. Further, by rotating the last subject in the trial-administration sequence (maximum odor) to the first or "donor" position (no odor), it should be possible to demonstrate that shifting subjects from high odor buildup (strong, appropriate patterning) to no odor results in the immediate disruption of patterned responding.

A final design condition of the present study was 
the introduction of naive animals into the larger group of "experienced" rats. Placement of the first two naive animals immediately after the first, or "donor," animal in the sequence should expose them to relatively weak odors. Placement of the second pair of naive subjects at the end of the sequence should expose them to a stronger buildup of odor. Hence, the second pair of naive subjects might be expected to acquire patterned responding more quickly than the first pair of naive subjects.

\section{METHOD}

\section{Subjects}

Seventeen, male Holtzman albino rats served as subjects. All animals were approximately 90 days old at the beginning of the experiment and were housed in individual cages with water freely available. Upon arrival from the supplier, the animals were assigned randomly to two groups: original $(O)$ subjects $(n=13)$ and naive $(N)$ subjects $(n=4)$. Seven days before the start of the experiment, the $O$ subjects were placed on a food-deprivation schedule that maintained them at $85 \%$ of their free-feeding body weights. Maintenance of the deprivation schedule took place following each daily experimental session.

\begin{abstract}
Apparatus
A single straight runway, consisting of a $38.10-\mathrm{cm}$ gray startbox, 91.44-cm black run section, and 30.48-cm black goalbox, served as the experimental apparatus. Two Masonite guillotine doors separated the start and run sections, and run and goal sections, respectively. Three photoelectric beams located $15.20,92.40$, and $116.80 \mathrm{~cm}$ beyond the start door, in conjunction with a microswitch located on the start door and three digital timers, yielded start, run, and goal latencies. A plastic receptacle recessed into the distal end of the goalbox served as the goal cup. The goal cup was manually loaded prior to each trial. However, a pellet dispenser filled with $45-\mathrm{mg}$ Noyes pellets was located adjacent to the goalbox. The pellet dispenser delivery tube extended into the goal cup. A piece of screen wire affixed to the end of the delivery tube prevented pellets from falling into the goal cup. This arrangement provided a constant source of food odor in the goalbox. A thin sheet of transparent plastic covered the entire top of the runway and prevented the dissipation of odors.
\end{abstract}

\section{Design and Procedure}

Runway training was preceded by a 4-day pretraining phase. On Pretraining Days 1-2, the subjects were handled and tamed. On the 3rd and 4th days of pretraining, each subject received a 5 -min-exploration period in the unbaited apparatus. During all pretraining days, the subjects were habituated to the 45-mg Noyes pellets in the home cage.

Phase 1. At the beginning of Phase 1, the $O$ subjects were randomly assigned a permanent number (1-13). These subjects were run in this order on all days of Phase 1 . During this phase, eight daily trials $(4 R, 4 N)$ were administered in a double-alternation (RRNNRRNN) sequence. During all phases of the experiment, $\mathrm{R}$ and $\mathrm{N}$ events consisted of $1245-\mathrm{mg}$ Noyes pellets and $30-\mathrm{sec}$ confinement to the empty goalbox, respectively. Phase 1 lasted 13 days (104 trials).

Phase 2. Phase 2 lasted 8 days (64) trials. Each animal in the O subjects group received eight daily trials in the doublealternation sequence. A subject-rotation procedure was begun on the first day of Phase 2 . This procedure involved the daily rotation of the last subject in the previous day's running sequence to the first position in the sequence. For example, Subject 13 on the last day of Phase 1 became Subject 1 on Day 1 of Phase 2, and so forth.

Phase 3. Prior to the start of Phase 3, the four animals in the
$\mathrm{N}$ subjects group were placed on food deprivation and administered pretraining procedures as previously described. The time period elapsed between the initiation of these procedures for the $\mathrm{N}$ subjects and the start of Phase 3 was the same as the time elapsed between the initiation of these procedures and the start of Phase 1 for the $O$ subjects. At the start of Phase 3 , the $N$ subjects were assigned randomly to two equal pairs $(n=2)$. In turn, these pairs were assigned randomly to occupy the 2 nd and $3 \mathrm{rd}$ and the 14th and 15 th positions in the running sequence. Thus, two pairs of naive animals were inserted at two distinct points in the $O$ subjects' running order, immediately after $O$ Subject 1 and immediately after the last $O$ subject. The sequence that was in effect for the $O$ subjects on the last day of Phase 2 remained in effect for the duration of Phase 3.

\section{RESULTS}

\section{Statistical Procedures}

The eight daily latencies for each subject were reciprocated and multiplied by the appropriate constant to yield speed scores (meters/second). Prior to analysis, the speed scores for the eight-trial doublealternation sequence were combined as follows: The first two trials were averaged to yield a composite $\mathbf{R}_{\mathbf{1}}$ score, the next two trials were averaged to yield a composite $\mathrm{N}_{1}$ score, and so forth. Hence, the daily double-alternation performance was reduced to four scores for each subject. Significant effects were further investigated by the Newman-Keuls procedure. The data from the initial subject in the trial-administration sequence was not included in the statistical analyses, since this subject was the donor animal for the remaining subjects. Results of the start, run, and goal analyses will be presented in all cases. However, as the most pronounced odor-related behavioral effects were observed in the goal measure, only these figures will be presented.

Phase 1. The $O$ subjects were subdivided into two squads $(n=4)$ for the purpose of data analysis. Squad 1 (low odor buildup) contained Subjects $2,3,4$, and 5 in the trial-administration sequence, while Squad 2 (high odor buildup) contained Subjects 10, 11, 12, and 13. A squads $\times \mathrm{R}-\mathrm{N} \times$ days analysis of variance was performed on the data from the last 9 days of Phase 1. Figure 1 shows the goal-measure performance of Squads 1 and 2. Supportive of an odorbuildup interpretation, this figure clearly demonstrates that Squad 2 developed appropriate patterning earlier in training, and maintained such responding more strongly throughout Phase 1, than did Squad 1. A somewhat unexpected result was the finding that the $R$ speeds of Squad 2 were significantly $(p<.05)$ faster than the $R$ speeds of Squad 1 on Days 5-12. As previous small-group odor studies have typically utilized within-subjects designs (e.g., Davis, Prytula, Noble, \& Mollenhour, 1976; Prytula \& Davis, 1974, 1976) or between-subject designs involving animals tested under the effects of odors produced by donor subjects injected with different drugs (e.g., Davis \& Prytula, 1979), primary attention has 


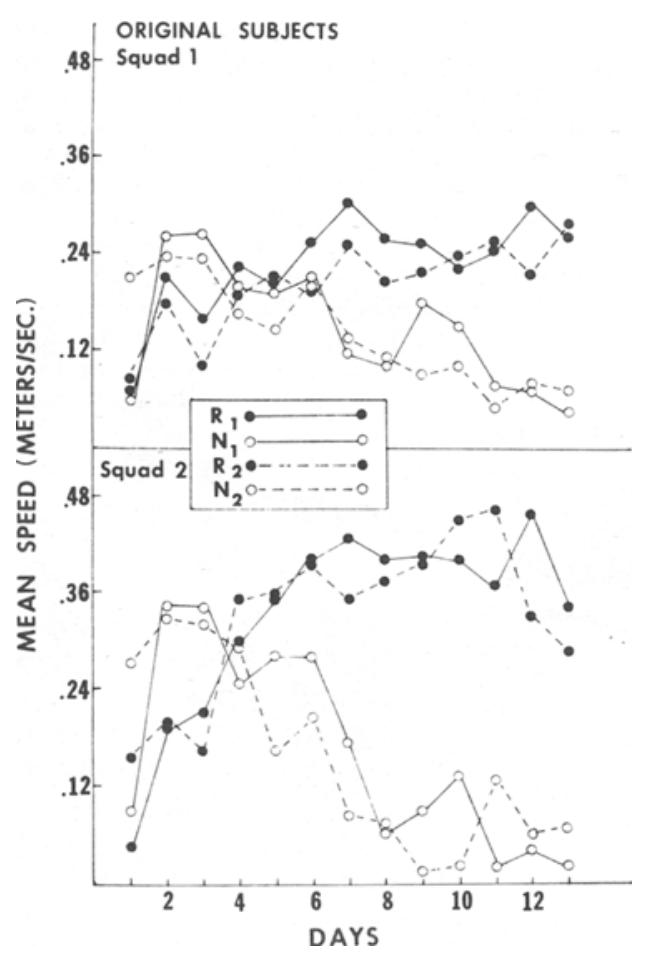

Figure 1. Mean $\mathbf{R}$ and $\mathbf{N}$ goal speeds (meters/second) for the original subjects: Squad 1 (first in training sequence) and Squad 2 (last in training sequence)-Phase 1.

been given to the depression and/or increase of $\mathrm{N}$-trial speeds. Consequently, the presence or absence of the odor of nonreward has been the central topic of much of the odor hypothesis. However, the R-speed differences found in the present study suggest that reward odor also accumulates. This finding would appear to make a significant addition to the odor literature.

Statistical analyses corroborate these graphical impressions: start, $\mathrm{R}-\mathrm{N} \times$ days, $\mathrm{F}(8,48)=3.09, \mathrm{p}<.01$; run, $\mathrm{R}$ vs. $\mathrm{N}, \mathrm{F}(1,6)=21.42, \mathrm{p}<.003$; days, $\mathrm{F}(8,48)$ $=5.62, \mathrm{p}<.001 ;$ Squad $1 /$ Squad $2 \times \mathrm{R}-\mathrm{N}, \mathrm{F}(1,6)$ $=5.79, \mathrm{p}<.05 ; \mathrm{R}-\mathrm{N} \times$ days, $\mathbf{F}(8,48)=6.71, \mathrm{p}<.001 ;$ Squad 1/Squad $2 \times$ days, $F(8,48)=2.30, p<.05$; Squad 1 /Squad $2 \times R-N \times$ days, $F(8,48)=3.14$, $\mathrm{p}<.001 ;$ goal, $\mathrm{R}$ vs. $\mathrm{N}, \mathrm{F}(1,6)=134.64, \mathrm{p}<.001$; days, $F(8,48)=3.01, p<.001$; Squad $1 /$ Squad $2 \times$ $\mathrm{R}-\mathrm{N}, \mathrm{F}(1,6)=18.72, \mathrm{p}<.004 ; \mathrm{R}-\mathrm{N} \times$ days, $\mathrm{F}(8,48)$ $=6.02, \mathrm{p}<.001$; and Squad 1/Squad $2 \times \mathrm{R}-\mathrm{N} \times$ days, $F(8,48)=2.18, p<.05$. Further comparisons revealed that significant $\mathbf{R}-\mathbf{N}$ differences first appeared in the goal on Day $5(p<.01)$ in the Squad 2 (last four) subjects and on Day 7 in the Squad 1 (first four) subjects $(p<.05)$. Similar results were observed in the start and run measures.

Phase 2. During Phase 2, eight subjects were in- dividually rotated (one rotation per day) from the last position in the trial-administration sequence to the first position. As can be seen from Figure 2, this change in position resulted in an immediate disruption of the discrimination. When an animal is shifted to the first position in the group, there is a distinct odor-cue change. Under this condition, the animal is tested in a clean, unmarked apparatus. Hence, despite the strong patterning that was developed and maintained throughout Phase 1 , nondifferential responding immediately occurred when each animal was rotated. Although these results are readily deducible from previously reported odor data, they do serve to underscore the potency of odor cues in the development and maintenance of instrumental responding. As the daily subject-rotation procedure resulted in changes in the subject composition of Squads 1 and 2, statistical analyses were not performed on the O subjects' data. However, visual inspection indicated that appropriate patterning was maintained by these subjects.

Phase 3. During Phase 3, the subject-rotation procedures were discontinued and Phase 1 conditions were reintroduced for the $O$ subjects. Additionally, the two pairs of $\mathrm{N}$ subjects were introduced into the trial-administration sequence during Phase 3.

Mean goal speeds for the $\mathrm{O}$ subjects (Squads 1 and 2) and the two pairs of N subjects are shown in Fig-

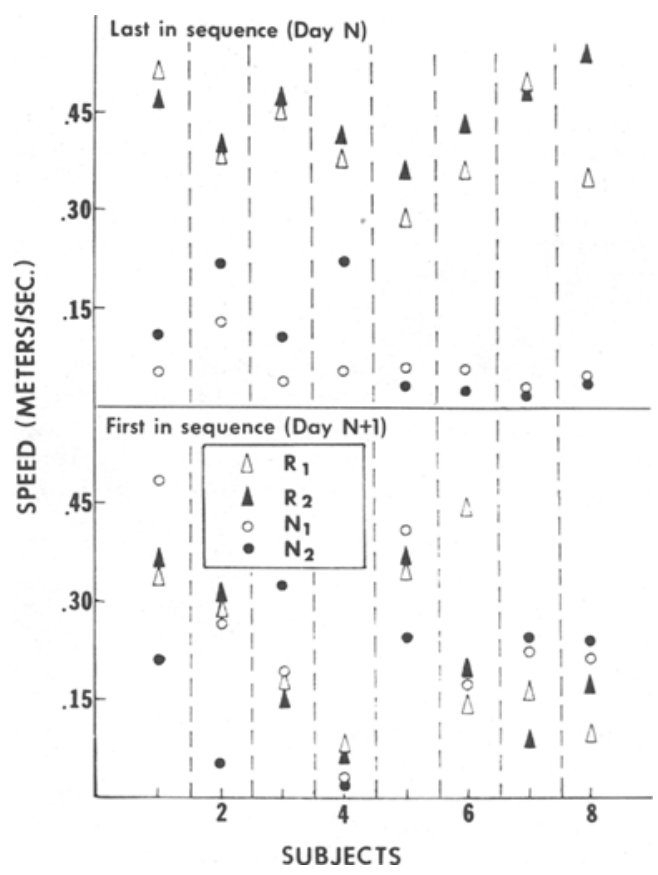

Figure 2. Mean $\mathbf{R}$ and $\mathbf{N}$ goal speeds (meters/second) for each of the eight subjects that were rotated from the last position (upper panel, Day $\mathbf{N}$ ) to the first position (lower panel, Day $\mathbf{N}+1$ ) in the trial-administration sequence-Phase 2. 


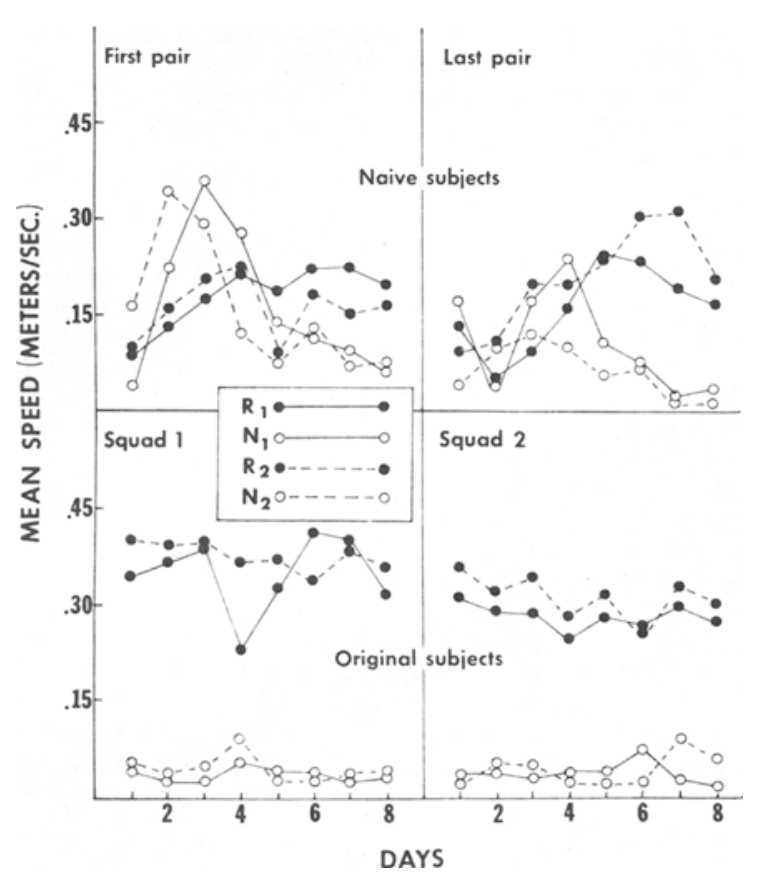

Figure 3. Mean $R$ and $\mathbf{N}$ goal speeds (meters/second) for the Naive subjects (upper panel): first pair and last pair; and the original subjects (lower panel): Squad 1 (first in training sequence) and Squad 2 (last in training sequence)-Phase 3.

ure 3. As can be seen, appropriate double-alternation patterning was maintained throughout Phase 3 by the $O$ subjects. Statistical analyses, similar to those performed on the Phase 1 data, indicated that significant double-alternation performance was established in all measures: start, $\mathrm{R}-\mathrm{N} \times$ days, $\mathrm{F}(7,42)=2.10$, $\mathrm{p}<.05 ;$ run, $\mathrm{R}$ vs. $\mathrm{N}, \mathrm{F}(1,6)=154.15, \mathrm{p}<.001$, and $\mathrm{R}-\mathrm{N} \times$ days, $\mathrm{F}(7,42)=3.21, \mathrm{p}<.01$; and goal, $\mathrm{R}$ vs. $\mathrm{N}, \mathrm{F}(1,6)=458.32, \mathrm{p}<.001$; days, $\mathrm{F}(7,42)=2.26$, $\mathrm{p}<.05 ;$ Squad $1 /$ Squad $2 \times \mathrm{R}-\mathrm{N}, \quad F(1,6)=6.22$, $\mathrm{p}<.05$; and $\mathrm{R}-\mathrm{N} \times$ days, $\mathrm{F}(7,42)=2.44, \mathrm{p}<.05$. Subsequent comparisons of the R-N $\times$ data interactions showed that, with the exception of Day 4, all R-N differences ( $R$ faster than $\mathbf{N}$ ) were significant $(p<.05)$ in all measures.

Inserting naive animals at the first positions (first pair) and last positions (last pair) within the $O$ subjects sequence resulted in distinctive differences. As can be seen from Figure 3, the last pair of naive animals acquired the discrimination much faster than the first pair of naive animals. Statistical analyses indicated that significant effects were shown in the run and goal measures [run, $\mathrm{R}$ vs. $\mathrm{N}, \mathrm{F}(1,2)=32.60$, $\mathrm{p}<.03$; days, $F(7,14)=3.36, \mathrm{p}<.05$; first pair $/$ last pair $\times \mathrm{R}-\mathrm{N}, \mathrm{F}(1,2)=161.40, \mathrm{p}<.006$; goal, $\mathrm{R}$ vs. $\mathrm{N}, \mathrm{F}(1,2)=41.34, \mathrm{p}<.02$; first pair/last pair $\times \mathrm{R}-\mathrm{N}, \mathrm{F}(1,2)=32.44, \mathrm{p}<.02$; and $\mathrm{R}-\mathrm{N} \times$ days,
$F(7,14)=9.21, p<.0001]$. Significant $R$ vs. $N$ differences were shown by the last pair on Days 6-8 in the run measure, and on Days 5-8 in the goal measure. Patterned responding did not develop for the first pair of subjects in either the start or run measure.

\section{DISCUSSION}

The present results indicate that when a larger group of subjects is run, R-N discriminations are established in all measures of the runway. In previous odor research using small groups (e.g., Ludvigson \& Sytsma, 1967; Prytula \& Davis, 1974, 1976; Prytula, Davis, Allen, \& Taylor, 1980), pattern responding was not obtained in the start section of the apparatus. With the larger group there is, theoretically, a greater buildup and accumulation of odors in the goal area. In turn, these more potent odors disseminate farther from the goal area back toward the run and start segments to establish and maintain appropriate responding in these sections. Likewise, the finding that responding is enhanced in naive animals appearing in the terminal positions of the sequence is supportive of this proposed odor buildup.

When animals were rotated from the last position in the training sequence to the first or "donor" position (Phase 2), there was an immediate loss of pattern responding. As the initial subjects were rotated deeper into the sequence, there was a rapid shift in behavior towards discriminative responding. The finding that the rotation procedure had little, if any, effect upon the performance of subsequent animals is supportive of data reported by Eslinger and Ludvigson (1980) indicating that there is commonality of trial-engendered odors between animals.

As Voorhees (1980) has shown that certain cells in the medial olfactory bulb of the rat responded in opposite directions to odors of reward and nonreward, it would seem reasonable to predict an accumulative effect for reward odors as well as nonreward odors. As mentioned, previous odor studies have focused upon manipulations primarily involving considerations of nonreward odor. The Phase 1 finding that the odor of reward also appears to accumulate certainly helps to provide a more complete picture of the odor phenomenon.

Lastly, it is interesting to note that the pattern responding shown by the last pair of naive subjects (Phase 3) developed somewhat sooner in training than has been the case in small-group-odor studies. Certainly, it can be argued that these subjects were being trained under conditions of intensified odor. However, the rapidity with which the R-N discrimination was acquired does suggest that the rat may well be biologically "prepared" (Seligman, 1970) to respond appropriately to reward and nonreward odors. In this regard, the naive subjects data is clearly mir- 
rored in the Phase 1, Squad 1 vs. Squad 2, performance of the original subjects. Here it can be seen (see Figure 1) that the last subjects in the training sequence (Squad 2) had established strong, appropriate patterning by Day 5 . (Actually, the onset of patterning appears to have occurred on Day 4). Thus, under intensified odor conditions, odor-cue saliency can be seen to easily override any carry-over effects of the reinforcement schedule very early in training.

\section{REFERENCES}

CApaldi, E. J. Memory and learning: A sequential viewpoint. In W. K. Honig \& P. H. R. James (Eds.), Animal memory. New York: Academic Press, 1971.

Davis, S. F., \& Prytula, R. E. Odor-mediated runway performance of the rat as a function of Thorazine injection. Bulletin of the Psychonomic Society, 1979, 13, 293-296.

Davis, S. F., Prytula, R. E., Noble, M. J., \& Mollenhour, M. N. Motivational specificity of the signal value of odor cues. Animal Learning \& Behavior, 1976, 4, 407-410.

Eslinger, P. J., \& Ludvigson, H. W. Commonality among rats in production reward and nonreward odors. Bulletin of the Psychonomic Society, 1980, 16, 191-193.

Lunvioson, H. W. Runway behavior of the rat as a function of intersubject reward contingencies and constancy of daily reward schedule. Psychonomic Science, 1969, 15, 41-43.

Ludvigson, H. W., \& SYTsma, D. The sweet smell of success: Apparent double alternation in the rat. Psychonomic Science, 1967, 9, 283-284.

Mellgren, R. L., Fouts, R. S., \& Martin, J. W. Approach and escape to conspecific odors of reward and nonreward. Animal Learning \& Behavior, 1973, 1, 129-132.

Prytula, R. E., \& Davis, S. F. Runway performance as a function of positively and negatively correlated olfactory cues. Psychological Reports, 1974, 35, 735-740.

Prytula, R. E., \& Davis, S. F. The relationship between locus of odor cues and double-alternation responding in the rat. Animal Learning \& Behavior, 1976, 4, 352-356.

Prytula, R. E., Davis, S. F., Allen, D. D., \& Taylor, R. D. Transfer of single- and double-alternation patterning as a function of odor cues. Bulletin of the Psychonomic Society, 1980, 15, 131-134.

Seago, J. D., Ludvigson, H. W., \& Remley, N. R. Effects of anosmia on apparent double-alternation in the rat. Journal of Comparative and Physiological Psychology, 1970, 71, 435-442.

Seligman, M. E. P. On the generality of the laws of learning. Psychological Review, 1970, 77, 406-418.

VOORHEEs, J. W. Single cell recording in the rat olfactory bulb. Unpublished doctoral dissertation, Texas Christian University, 1980.

(Manuscript received April 2, 1981; revision accepted for publication July 23, 1981.) 